\title{
PENGARUH TRUST, PERCEIVED VALUE, BRAND IMAGE DAN SATISFACTION TERHADAP REPURCHASE INTENTION BATIK AIR DI JAKARTA DAN TANGERANG
}

\author{
Adeline Felicia Lianto \\ Program Studi Magister Manajemen Universitas Tarumanagara \\ adelinefelicia20@gmail.com
}

\begin{abstract}
The aim of this research is to find out whether trust, perceived value, brand image and satisfaction give impacts on repurchase intention in flight industry. The samples are collected by using convenience method by giving out questionnaires to 122 customers of a flight company in Jakarta and Tangerang who have experience of using this flight for at least 2 times in last 5 years. The technique of data analysis used in this research is multiple regression analysis. The results showed that: (a) there is a significant and positive effects between trust and repurchase intention; (b) perceived value do not create significant impact towards repurchase intention; (c) brand image gives significant and positive effect to repurchase intention; (d) there is a significant and positive effects between satisfaction and repurchase intention.
\end{abstract}

Keywords: Trust, Perceived Value, Brand Image, Satisfaction, Repurchase Intention

\section{PENDAHULUAN}

Tingkat kebutuhan aktivitas leisure di Indonesia terus meningkat berbanding lurus dengan penggunaan jasa penerbangan. Faktanya berdasarkan informasi yang didapat dari Badan Pusat Statistik (BPS) dilansir oleh cnnindonesia.com, konsumsi yang berkaitan dengan rekreasi dan budaya meningkat secara signifikan sampai 6,5 persen hingga akhir tahun 2017. Menurut Sri Soelistyowati, deputi bidang Neraca dan Analisis Statistik BPS pada artikel yang ditulis oleh Setiawan (2017), aktivitas leisure yang mulai menjadi tren dipengaruhi dengan adanya sisi permintaan dari segi pekerjaan yang tekanannya tinggi, begitu juga penawaranpenawaran promosi dan paket wisata yang murah. Tren terbaru yang terus berkembang ini dijadikan suatu peluang bagi Batik Air di bawah PT Lion Mentari Airlines untuk mengembangkan layanan penerbangannya ke tahap berikutnya karena memberi dampak kepada masyarakat untuk memenuhi kebutuhan dan gaya hidup mereka saat membutuhkan waktu untuk beristirahat dari pekerjaan.

PT Lion Mentari Airlines ini sangat dikenal dengan low-cost carrier yang juga mendukung tagline perusahaan, "We Make People Fly". Wings Air, Batik Air, Lion Bizjet, Malindo (dari Malaysia) dan Thai Lion (dari Thailand) merupakan perusahaan penerbangan bagian dari PT Lion Mentari Airlines (Lionair.com). Beberapa tahun belakangan maskapai Lion Air dinilai sebagai penerbangan yang suka terlambat/delay seperti dilansir dari artikel On Time Performance (OTP) di dephub.go.id, sedangkan Batik Air mendapatkan peringkat dua di Asia Tenggara setelah Singapura Airlines dengan selisih 0,2\%. "Selain di Asia Tenggara, Batik Air juga unggul di Indonesia. Ketepatan waktu penerbangan Batik Air di Indonesia 88,66\%, mengungguli maskapai Garuda Indonesia yang hanya 88,53\% dan Citilink 88,53\%." (batikair.com).

Menurut Fang, Chiu dan Wang (2011), kemungkinan bisa terjadinya repurchase intention dapat dilihat secara subjektif, bahwa seseorang akan terus membeli produk dari vendor atau toko online di masa depan. Customer satisfaction sangat penting bagi keberhasilan toko online karena hal ini merupakan pendorong utama fenomena pasca pembelian, seperti repurchase intention. Salah satu tolak ukur keberhasilan perusahaan di bidang jasa yaitu 
pelanggan menggunakan layanan dari perusahaan yang sama, atau terjadinya repurchase intention. Pada penelitian yang dilakukan oleh Saleem, Zahra dan Yaseen (2017), repurchase intention menjadi faktor paling penting untuk bertahan dan berkembang dalam persaingan sektor pelayanan. Selain itu, jika perusahaan fokus mempertahankan pelanggan dibanding menarik perhatian pelanggan baru atau calon pelanggan, tidak hanya repurchase intention akan timbul tapi juga lebih menguntungkan untuk usaha jangka panjang.

Menurut Anderson dan Weitz (1989) dalam Fang, Chiu dan Wang (2011), trust pada penjual merupakan kunci penting untuk membangun loyalitas pelanggan dan menjaga hubungan berkelanjutan antara pembeli dan penjual. Lee, Eze dan Ndubisi (2011) menemukan bahwa trust berpengaruh signifikan terhadap repurchase intention. Selain trust, Lee, Eze, Ndubisi (2011) juga menyatakan perceived value memiliki pengaruh signifikan terhadap repurchase intention. Penawaran atas perceived value yang tinggi dapat meningkatkan kemungkinan pelanggan untuk kembali dan melakukan transaksi kembali di masa depan.

Dalam penelitian Ayutthaya (2013) membahas tentang brand image dan repurchase pada Low Cost Carriers menemukan bahwa brand image memiliki dampak yang signifikan secara statistik terhadap repurchase intention. Ada empat dimensi yang harus dipertimbangkan untuk mengukur brand secara efektif. Lin (2008) menjelaskan bahwa brand image memicu adanya keinginan yang jauh lebih tinggi untuk membeli ulang merek yang sama. Sementara Dholakia \& Zhao (2010) menyatakan bahwa korelasi antara satisfaction dan repurchase intention sangat tinggi. Park dan Kim (2003) menjelaskan ada tambahan konsep untuk transaksi online yaitu "kepuasan informasi". Konsep ini mengusung satisfaction sebagai reaksi emosional yang dirasakan pelanggan atas pengalaman dari keseluruhan layanan yang disediakan. Ketika pelanggan merasa puas terhadap layanan dari perusahaan terutama pada penjualan berbasis online, repurchase intention dapat terus meningkat.

Tujuan dari penelitian ini adalah untuk mengetahui: (1) pengaruh trust terhadap repurchase intention; (2) pengaruh perceived value terhadap repurchase intention; (3) pengaruh brand image terhadap repurchase intention; (4) pengaruh satisfaction terhadap repurchase intention. Hasil penelitian ini diharapkan dapat memberikan informasi kepada perusahaan jasa penerbangan dalam pengambilan keputusan untuk menjaga dan meningkatkan trust, perceived value, brand image, dan satisfaction agar meningkatkan terjadinya repurchase intention.

\section{Pengaruh Trust terhadap Repurchase Intention}

Lee, Eze dan Ndubisi (2011) mengatakan bahwa trust berpengaruh signifikan terhadap repurchase intention. Hasil penelitian ini juga menyimpulkan bahwa retail online harus membangun reputasi dan trust yang membuat konsumen terus membeli dari mereka. Selain itu, perusahaan harus menjaga informasi privasi pelanggan. Membangun trust dan reputasi yang baik akan menambahkan nilai dan kegunaan untuk berkomunikasi dengan konsumen. Hasil penelitian dari Zboja dan Voorhees (2006) menyatakan bahwa brand trust mempunyai pengaruh positif terhadap repurchase intention secara signifikan. Dalam pengembangan private brand products yang dapat dipercaya oleh pelanggan, retailers meningkatkan kesempatan dimana trust bisa tercipta dan pelanggan akan tetap setia, sehingga meningkatkan kemungkinan pelanggan melakukan repurchase intention.

Berbeda dengan Fang, Chiu dan Wang (2011), trust mempunyai efek pada repurchase intention secara garis besar berpengaruh signifikan. Cara untuk meningkatkan trust yaitu ketika berinteraksi dengan konsumen, perusahaan harus memperlakukan dengan hormat, ramah, dan sopan. Kualitas dari perlakuan tersebut dapat memberi tanda kepada konsumen bahwa perusahaan peduli terhadap mereka yang tentunya dapat meningkatkan ekonomi berdasarkan interaksi tersebut. 


\section{Pengaruh Perceived Value terhadap Repurchase Intention}

Berdasarkan hasil penelitian dari Lee, Eze dan Ndubisi (2011), perceived value berpengaruh signifikan terhadap repurchase intention. Penawaran atas perceived value yang tinggi dapat meningkatkan kemungkinan pelanggan untuk kembali dan melakukan transaksi kembali di masa depan. Molinari, Abratt dan Dion (2008) juga berpendapat bahwa value memiliki hubungan positif terhadap repurchase intention secara signifikan. Pada penelitian tersebut, disebutkan manajer harus menyadari akan perceived value pelanggan. Semakin baik manajer dapat menelaah keinginan pelanggan, semakin sukses pelayanan yang ditawarkan perusahaan dapat memenuhi ekspektasi pelanggan yang dapat memicu terjadinya repurchase intention.

\section{Pengaruh Brand Image terhadap Repurchase Intention}

Brand image memiliki hubungan positif dengan repurchase intention seperti yang dikatakan Ayutthaya (2013). Pada penelitian yang membahas maskapai penerbangan tersebut, Ayutthaya (2013) menemukan bahwa maskapai dapat menciptakan brand image positif dalam pikiran konsumen agar mendorong pembelian kembali. Lin (2008) juga menambahkan bahwa brand image dapat meningkatkan tingkat keinginan yang jauh lebih tinggi untuk membeli ulang merek yang sama. Menurut Ebrahimi dan Tootoonkavan (2014), brand image mempunyai efek positif secara langsung ke repurchase intention. Lain halnya dengan penemuan Saleem, Zahra dan Yaseen (2017) dimana brand image cenderung tidak memengaruhi keputusan repurchase intention pada mediasi yang sederhana. Namun brand image berpengaruh signifikan terhadap repurchase intention dengan dimediasi WOM. Walau sebelumnya brand image telah dinyatakan berhubungan positif dengan repurchase intention.

\section{Pengaruh Satisfaction terhadap Repurchase Intention}

Menurut Ebrahimi dan Tootoonkavan (2014) satisfaction mempunyai efek positif langsung terhadap repurchase intention. Dholakia dan Zhao (2010) juga sependapat bahwa satisfaction dan repurchase intention memiliki korelasi yang sangat tinggi. Penelitian yang dilakukan Fang, Chiu dan Wang (2011) menemukan bahwa satisfaction menjadi variabel yang paling dominan memengaruhi repurchase intention. Berbeda dengan hasil penemuan Hellier et al (2003), dan Chen dan Chen (2017) dimana satisfaction tidak berpengaruh dan tidak memiliki efek yang signifikan terhadap repurchase intention.

\section{HIPOTESIS PENELITIAN}

Berdasarkan paparan di atas, maka hipotesis penelitian adalah sebagai berikut:

H1: Terdapat pengaruh positif trust terhadap repurchase intention.

$\mathrm{H} 2$ : Terdapat pengaruh positif perceived value terhadap repurchase intention.

H3: Terdapat pengaruh positif brand image terhadap repurchase intention.

$\mathrm{H} 4$ : Terdapat pengaruh positif satisfaction terhadap repurchase intention.

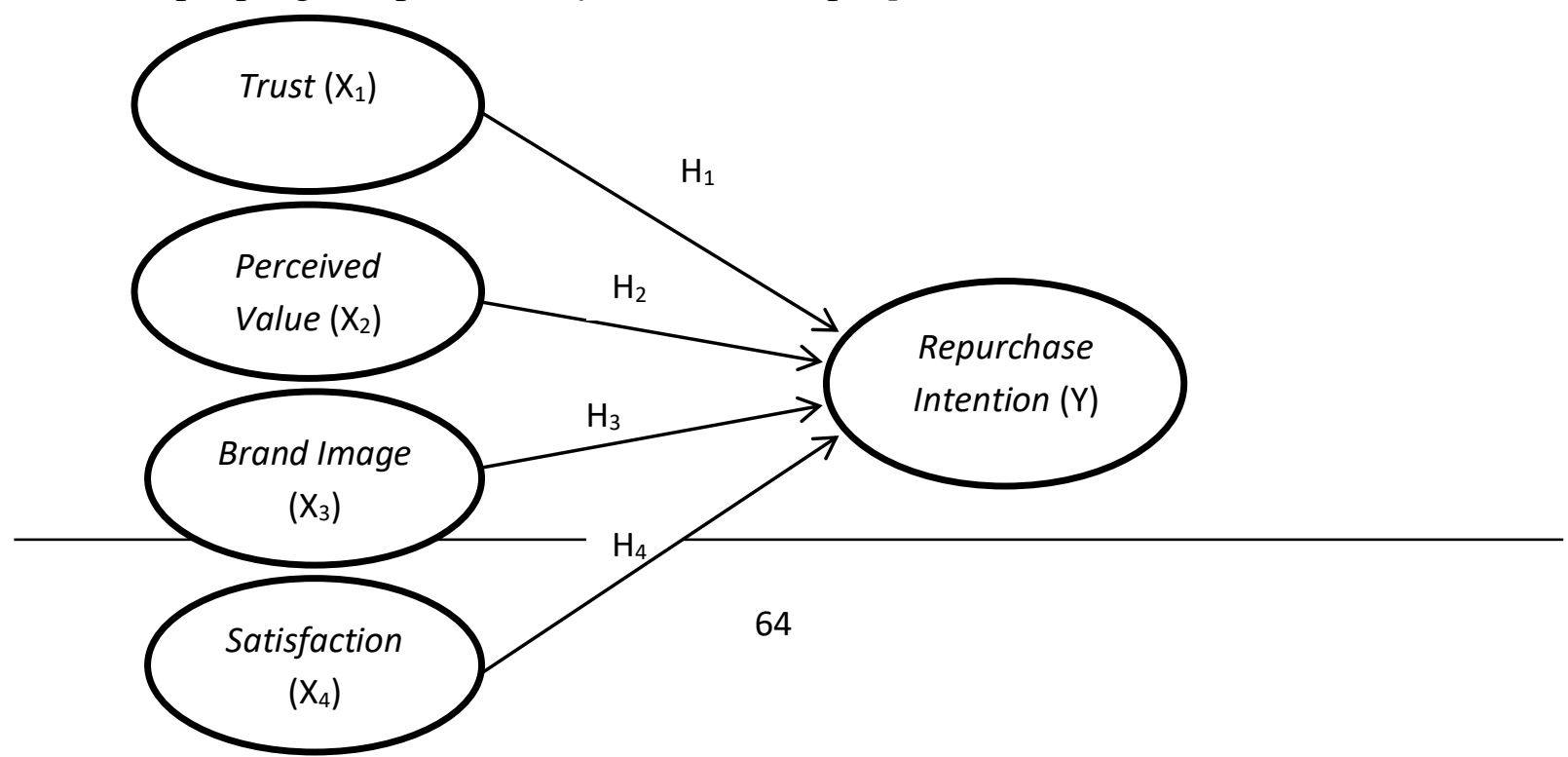




\section{METODOLOGI}

\section{Populasi dan Metode Pengambilan Sampel}

Populasi dalam penelitian ini adalah seluruh pelanggan Batik Air yang tidak terbatas jumlahnya karena terus bertambah, berdomisili di Indonesia maupun di luar negeri dan melakukan perjalanan dengan penerbangan Batik Air minimal satu kali. Dalam penelitian ini, convenience sampling digunakan sebagai teknik penarikan sampel karena dilakukan tanpa mekanisme tertentu. Sampel dalam penelitian ini meliputi pelanggan yang mempunyai pengalaman menggunakan jasa penerbangan Batik Air lebih dari satu kali. Dengan kriteria responden berdomisili di Jakarta dan Tangerang. Sugiyono (2013) menyarankan untuk pemilihan besaran jumlah sampel sebanyak 5-10 kali jumlah indikator yang diestimasi. Dalam penelitian ini, ada 21 indikator, sehingga dapat ditentukan jumlah responden harus dalam rentang 105-210 responden.

Responden yang terkumpul yang sesuai dengan kriteria sebanyak 122 orang. Setelah mengetahui bahwa tiap item pernyataan layak digunakan, kemudian data tersebut dianalisis mulai dari deskripsi subjek penelitian yaitu bahwa mayoritas responden adalah perempuan berusia 50 tahun ke atas, berprofesi sebagai Wirausaha, dengan pengeluaran per bulannya lebih dari Rp 10.000.000,- dan menggunakan kelas ekonomi.

\section{Variabel dan Pengukuran}

Pada penelitian ini, variabel independen trust, perceived value, brand image, dan satisfaction, sedangkan variabel dependen repurchase intention diukur dengan menggunakan beberapa item-item pernyataan yang diadaptasi dari beberapa penelitian terdahulu pada tabel di bawah ini. Setiap item-item pernyataan pada kuesioner akan diukur dengan menggunakan 5 poin skala Likert dimana 1 menunjukkan "Sangat Tidak Setuju" sampai 5 menunjukkan "Sangat Setuju".

\section{Tabel 1. Variabel dan Pengukuran}

\begin{tabular}{|c|c|c|}
\hline Variabel & Item & Sumber \\
\hline \multirow{4}{*}{ Trust } & Perusahaan ini selalu jujur & \multirow{4}{*}{$\begin{array}{l}\text { Fang, Chiu, dan } \\
\text { Wang (2011) dan } \\
\text { Zboja dan Voorhees } \\
\text { (2006) }\end{array}$} \\
\hline & $\begin{array}{l}\text { Perusahaan ini menepati janji dengan } \\
\text { pelanggan }\end{array}$ & \\
\hline & Perusahaan ini dapat dipercaya & \\
\hline & Perusahaan ini dapat diandalkan & \\
\hline \multirow{3}{*}{ Perceived Value } & $\begin{array}{l}\text { Layanan yang diterima sebanding dengan } \\
\text { besar uang yang dibayarkan }\end{array}$ & \multirow{3}{*}{$\begin{array}{l}\text { Hume dan Mort } \\
(2010)\end{array}$} \\
\hline & $\begin{array}{l}\text { Layanan yang diterima sebanding dengan } \\
\text { waktu dan usaha }\end{array}$ & \\
\hline & $\begin{array}{l}\text { Layanan diterima dengan baik sebanding } \\
\text { dengan waktu dan uang yang dibayarkan }\end{array}$ & \\
\hline \multirow{2}{*}{ Brand Image } & $\begin{array}{l}\text { Maskapai ini memiliki citra merek yang } \\
\text { kuat }\end{array}$ & \multirow{2}{*}{ Ayutthaya (2013) } \\
\hline & $\begin{array}{l}\text { Memiliki brand yang unik dan berbeda } \\
\text { dari maskapai lainnya }\end{array}$ & \\
\hline
\end{tabular}




\begin{tabular}{|c|c|c|}
\hline & $\begin{array}{l}\text { Brand image maskapai ini memenuhi } \\
\text { espektasi saya }\end{array}$ & \\
\hline & $\begin{array}{l}\text { Brand ini mencerminkan layanan } \\
\text { penerbangan berkualitas tinggi }\end{array}$ & \\
\hline & $\begin{array}{l}\text { Saya mengakui maskapai ini memiliki } \\
\text { brand yang positif }\end{array}$ & \\
\hline & $\begin{array}{l}\text { Saya mengevaluasi brand maskapai ini } \\
\text { sebagai maskapai yang berharga }\end{array}$ & \\
\hline \multirow{4}{*}{ Satisfaction } & $\begin{array}{l}\text { Saya puas dengan kualitas layanan (rute, } \\
\text { jadwal, biaya pengiriman, dll.) dan } \\
\text { customer relationship management dari } \\
\text { perusahaan ini }\end{array}$ & \multirow{4}{*}{$\begin{array}{l}\text { Shin et al (2017), } \\
\text { Molinari, Abratt, } \\
\text { dan Dion (2008), } \\
\text { dan Zboja dan } \\
\text { Voorhees (2006) }\end{array}$} \\
\hline & $\begin{array}{l}\text { Saya puas dengan pelayanan berkualitas } \\
\text { unggul yang disediakan perusahaan ini }\end{array}$ & \\
\hline & $\begin{array}{l}\text { Saya puas dengan keputusan saya } \\
\text { membeli produk ini }\end{array}$ & \\
\hline & $\begin{array}{l}\text { Saya puas dan sungguh menikmati } \\
\text { membeli produk ini }\end{array}$ & \\
\hline \multirow{4}{*}{$\begin{array}{l}\text { Repurchase } \\
\text { Intention }\end{array}$} & $\begin{array}{l}\text { Saya ingin terus menggunakan dan } \\
\text { membeli produk ini }\end{array}$ & \multirow{4}{*}{$\begin{array}{l}\text { Fang, Chiu, dan } \\
\text { Wang (2011), Chen } \\
\text { dan Chen (2017), } \\
\text { dan Zboja dan } \\
\text { Voorhees (2006) }\end{array}$} \\
\hline & $\begin{array}{l}\text { Ke depan, saya berniat menggunakan } \\
\text { layanan dari perusahaan ini }\end{array}$ & \\
\hline & $\begin{array}{l}\text { Saya akan menjaga hubungan dengan } \\
\text { perusahaan ini di masa depan }\end{array}$ & \\
\hline & $\begin{array}{l}\text { Saya akan melakukan bisnis dengan } \\
\text { perusahaan ini di masa depan }\end{array}$ & \\
\hline
\end{tabular}

\section{Metode Analisis Data}

Penelitian ini menggunakan program Statistical Product and Services Solution (SPSS) untuk menganalisa mulai dari uji validitas, uji reliabilitas, uji asumsi klasik, uji model regresi berganda, uji t, uji $\mathrm{F}$, dan uji $\mathrm{R}$-Square $\left(\mathrm{R}^{2}\right)$. Dalam penelitian ini, uji validitas dilakukan dengan melihat nilai corrected item-total correlation dari masing-masing faktor yang dinilai. Indikator yang dinyatakan valid, perlu diuji reliabilitasnya dengan melihat besaran nilai koefisien Cronbach Alpha. Hasil yang didapat dari pengujian tersebut yaitu semua variabel dinyatakan valid dan reliabel untuk digunakan dalam penelitian. Penelitian ini menggunakan analisis regresi berganda yang bertujuan untuk mengetahui pengaruh trust $\left(\mathrm{X}_{1}\right)$, perceived value $\left(\mathrm{X}_{2}\right)$, brand image $\left(\mathrm{X}_{3}\right)$, dan satisfaction $\left(\mathrm{X}_{4}\right)$ terhadap repurchase intention $(\mathrm{Y})$.

\section{ANALISA DAN PEMBAHASAN}

Tabel 2 di bawah ini merupakan hasil analisis uji hipotesis.

\section{Tabel 2. Hasil Pengujian Hipotesis}

\begin{tabular}{|lllll|}
\hline Hipotesis & B & Sig & Kesimpulan \\
\hline H1 & $\begin{array}{l}\text { Terdapat pengaruh positif antara trust dengan } \\
\text { repurchase intention konsumen pengguna jasa }\end{array}$ & 0,262 & 0,014 & Tidak ditolak \\
& $\begin{array}{l}\text { layanan penerbangan Batik Air di Jakarta dan } \\
\text { Tangerang }\end{array}$ & & & \\
H2 & $\begin{array}{l}\text { Terdapat pengaruh positif antara perceived } \\
\text { value dengan repurchase intention konsumen } \\
\text { pengguna jasa layanan penerbangan Batik Air } \\
\text { di Jakarta dan Tangerang }\end{array}$ & 0,072 & 0,438 & Ditolak \\
\hline
\end{tabular}




\begin{tabular}{|lllll|}
\hline H3 & $\begin{array}{l}\text { Terdapat pengaruh positif antara brand image } \\
\text { dengan repurchase intention konsumen } \\
\text { pengguna jasa layanan penerbangan Batik Air }\end{array}$ & 0,215 & 0,021 & Tidak ditolak \\
di Jakarta dan Tangerang & & & \\
H4 & $\begin{array}{l}\text { Terdapat pengaruh positif antara satisfaction } \\
\text { dengan repurchase intention konsumen } \\
\text { pengguna jasa layanan penerbangan Batik Air } \\
\text { di Jakarta dan Tangerang }\end{array}$ & & & \\
\end{tabular}

Berdasarkan hasil penelitian variabel pada pengujian hipotesis model regresi ganda, variabel $\left(\mathrm{X}_{1}\right)$ trust sesuai dengan penelitian Lee, Eze dan Ndubisi (2011) yang mengungkapan bahwa trust mempunyai pengaruh signifikan terhadap repurchase intention. Kesamaan juga ditemukan pada penelitian yang dilakukan Zboja dan Voorhees (2006) bahwa trust mempunyai pengaruh positif terhadap repurchase intention. Didukung pula dengan penelitian Fang, Chiu dan Wang (2011) yang menemukan bahwa trust berpengaruh signifikan terhadap repurchase intention.

Selanjutnya hasil dari variabel $\left(\mathrm{X}_{2}\right)$ perceived value berbeda dengan penemuan Lee, Eze dan Ndubisi (2011) yang menyatakan bahwa perceived value mempunyai pengaruh signifikan terhadap repurchase intention. Padahal Molinari, Abratt dan Dion (2008) juga berpendapat bahwa value memiliki hubungan positif terhadap repurchase intention secara signifikan.

Hasil penelitian yang menunjukkan pengaruh variabel $\left(\mathrm{X}_{3}\right)$ brand image dengan repurchase intention sama seperti penemuan Ayutthaya (2013) dimana hubungan antar variabel independen dan variabel dependen ini positif. Penemuan tersebut juga didukung Ebrahimi dan Tootoonkavan (2014) dimana brand image mempunyai efek positif secara langsung ke repurchase intention.

Variabel $\left(\mathrm{X}_{4}\right)$ satisfaction sama dengan penelitian Ebrahimi dan Tootoonkavan (2014) yang menyatakan ada efek positif langsung terhadap repurchase intention. Dholakia dan Zhao (2010) juga sependapat bahwa satisfaction dan repurchase intention memiliki korelasi yang sangat tinggi. Penelitian yang dilakukan Fang, Chiu dan Wang (2011) mendukung pernyataan sebelumnya bahwa satisfaction menjadi variabel yang paling dominan memengaruhi repurchase intention. Dapat disimpulkan responden dapat melakukan repurchase intention jika mereka merasa satisfied terhadap kualitas pelayanan dan customer relationship management dari perusahaan penerbangan tersebut.

\section{PENUTUP}

\section{Kesimpulan}

Berdasarkan hasil analisis penelitian ini, maka dapat disimpulkan bahwa repurchase intention dapat dipengaruhi secara signifikan dan positif oleh beberapa faktor antara lain variabel trust, brand image, dan satisfaction secara simultan, sedangkan perceived value tidak memberi pengaruh yang signifikan. Repurchase intention yang merupakan pengambilan keputusan untuk membeli layanan kembali di masa depan dengan penyedia layanan dapat terjadi berdasarkan tiap individu konsumen perusahaan penerbangan tersebut. Ketika konsumen sudah merasa satisfied, mempunyai trust dan terlebih didukung dengan brand image yang tertanam kuat dipikiran konsumen, maka repurchase intention bisa terus terjadi.

\section{Saran}

Terkait dengan hasil penelitian ini, maka peneliti akan memberikan beberapa saran yang bermanfaat bagi perusahaan dan peneliti lain, yaitu perusahaan penerbangan sudah terbukti dapat memuaskan pelanggan seperti pada hasil pengaruh satisfaction terhadap repurchase intention. Oleh karena itu, peneliti menyarankan agar terus meningkatkan kualitas layanan 
dan selalu memberikan kualitas unggul supaya semakin memuaskan pelanggan. Sebagai faktor kedua yang paling berpengaruh, perusahaan penerbangan tersebut sebaiknya tidak hanya membuat pelanggan memiliki kepercayaan kepada perusahaan, tapi juga bersikap jujur kepada pelanggan, sehingga tidak ada keraguan antara sebagian penumpang. Peneliti memberi saran agar perusahaan penerbangan tersebut dapat meningkatkan brand imagenya karena terbukti ketiga paling berpengaruh terhadap repurchase intention dimana brand image dari perusahaan harus lebih ditonjolkan lagi dengan mengangkat batik sebagai pembeda. Faktor-faktor yang memengaruhi terjadi repurchase intention tidak hanya satisfaction dan trust tapi juga brand image.

\section{DAFTAR PUSTAKA}

Ayutthaya, S. S. N. (2013). Impact of Perceived Service on Brand Image and Repurchase Intentions of Thai Passengers Towards Low Cost Carriers. Journal of Management, $11(2), 46-56$.

Chen dan Chen (2017). The Role of Customer Participation for Enhancing Repurchase Intention. Management Decision, 55 (3), 547-562.

Dholakia dan Zhao (2010). Effects of Online Store Attributes on Customer satisfaction and Repurchase intentions Effects of Online Store Attributes on Customer satisfaction and Repurchase Intentions. International Journal of Retail \& Distribution Management, 38 (7), 482-496.

Ebrahim dan Tootoonkavan (2014). Investigating the Effect of Perceived Service Quality, Perceived Value, Brand Image, Trust, Customer Satisfaction on Repurchase Intention and Recommendation to Other. European Journal of Business and Management, 6 (34), 181-186.

Fang, Chiu, Wang (2011). Understanding Customers' Satisfaction and Repurchase Intentions: An Integration of IS Success Model, Trust, and Justice. Internet Research, 21 (4), 479-503.

Hellier, Geursen, Carr, Rickard (2003). Customer Repurchase Intention: A General Structural Equation Model. European Journal of Marketing, 37 (11/12), 1762-1800.

Hume dan Mort (2011). The Consequence Of Appraisal Emotion, Service Quality, Perceived value And Customer satisfaction On Repurchase Intent In The Performing Arts. Journal of Services Marketing, 24 (2), 170-182.

Lee, Eze, Ndubisi (2011). Analyzing Key Determinants Of Online Repurchase Intentions. Asia Pacific Journal of Marketing and Logistics, 23 (2), 220-221.

Molinari, Abratt dan Dion (2008). Satisfaction, Quality and Value and Effects On Repurchase and Positive Word-Of-Mouth Behavioral Intentions In A B2B Services Contex. Journal of Services Marketing, 22 (5), 363-373.

Saleem, Zahra dan Yaseen (2017). Impact of Service Quality and Trust on Repurchase Intentions. Asia Pacific Journal of Marketing and Logistics, 29 (5), 1136-1159.

Sugiyono. (2013). Metode Penelitian Kuantitatif Kualitatif dan R\&D. Bandung: Alfabeta.

Zboja dan Voorhees (2006). The Impact of Brand Trust and Satisfaction on Retailer Repurchase Intentions. Journal of Services marketing, 20 (6), 381-390. 


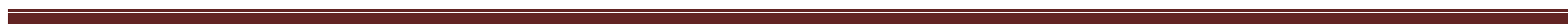
$\cdot$ 